\title{
An Introduction to the Health Promotion Perspective in the Health Care Services
}

\author{
Gørill Haugan and Monica Eriksson
}

\section{Abstract}

Currently, the world faces a shift to an older population. For the first time in the history, now most people can expect to live into their 60s and beyond. Within this trend of people living longer, many grow very old; 80, 90 and 100 years. Today, 125 million people are 80 years or older; the proportion of $\geq 80$ years increases the most. Age is not an illness, still most chronically ill are older people. Consequently, all countries in the world face major challenges to ensure that their health and social systems are ready to make the most of this demographic shift. Globally, finding new and effective ways to improve people's health is crucial. Thus, in the years to come, health promotive initiatives will become ever more important. Accordingly, learning how to reorient the health care sector in

\footnotetext{
G. Haugan $(\triangle)$

Department of Public Health and Nursing, NTNU Norwegian University of Science and Technology, Trondheim, Norway

Faculty of Nursing and Health Science, Nord University, Levanger, Norway e-mail: gorill.haugan@ntnu.no, gorill.haugan@nord.no
}

\section{Eriksson}

Department of Health Sciences, University West, Trollhattan, Sweden

e-mail: monica.eriksson@hv.se a health promotion direction is highly needed. The salutogenic approach seems useful for such a reorientation.

Salutogenesis is a resource-oriented theoretical approach which focuses on the origin of health along with people's abilities and capacities for well-functioning and wellbeing. Salutogenesis is an area of knowledge and learning, a way of relating to others, and a way of working in a health-promoting manner. From the salutogenic point of view, health is a movement on a continuum between ease and dis-ease. In this approach, no one is categorized as healthy or diseased; we are all somewhere between the imaginary poles of total wellness and total illness.

This chapter, as well as this book, comprehend the salutogenic health theory as a model of health and a life orientation, representing a vital theoretical basis for the health promotion field. Accordingly, this chapter presents some important points in the development of the health promotion field, followed by the core principles and strategies of health promotion and the promising potential of the salutogenic health theory.

\section{Keywords}

Health promotion $\cdot$ Salutogenesis .

Demographic trends $\cdot$ Non-communicable diseases $\cdot$ Reorienting the health services 


\section{$1.1 \quad$ Introduction}

\subsubsection{Demographic Trends}

Currently, the world faces a shift to an older population; 125 million people are now aged 80 years or older [1]. While this shift started in highincome countries (e.g. in Japan 30\% of the population are already over 60 years old), it is now low- and middle-income countries that are experiencing the greatest change. Today, for the first time in the history, most people can expect to live into their 60s and beyond [2]. Between 2015 and 2050 , the proportion of the world's population over 60 years will nearly double from $12 \%$ to $22 \%$; by 2050 , the world's population aged 60 years and older is expected to total two billion, up from 900 million in 2015 [1, 2]. All countries in the world face major challenges to ensure that their health and social systems are ready to make the most of this demographic shift [1]. Within this trend of people living longer, many grow very old; 80, 90 and 100 years. Today, 125 million people are 80 years or older; the proportion of $\geq 80$ years increases the most.

Thus, it is important to ensure that the extra years of life are worth living, despite chronic illnesses and loss of functionality. This is of great importance not only to the individual elderly, but also to the families, the local community and the municipality. However, there is little evidence showing that older adults today have better health than their parents had in their older years. Age is no disease; however, most chronically ill people today are older people. Increased age is followed by an increased incidence of functional and chronic comorbidities and diverse disabilities [3], which for many leads to the need for medical treatment and different levels of nursing care. Accordingly, the WHO's Action Plan on Aging and Health [4] highlights a global need of systems for providing long-term care to meet the needs of older people globally.

All countries face major challenges to ensure that their health and social systems are ready to make the most of these demographic shifts [2]. For instance, in the North Africa and the Middle East, due to very rapid demographic ageing, the estimated number of people with dementia is expected to grow exponentially, two million people in 2015 rising to four million in 2030 and ten million in 2050 [2], an increase of $329 \%$ from 2015 through to 2050, the second fastest in the world. Currently, North Africa and the Middle East are estimated to have the highest agestandardized prevalence globally [5].

The increasing burden due to cancer and other non-communicable diseases poses a threat to human development, which has resulted in global political commitments reflected in the Sustainable Development Goals as well as the World Health Organization (WHO) Global Action Plan on Non-Communicable Diseases. Between 2006 and 2016, the average annual age-standardized incidence rates for all cancers combined increased in 130 of 195 countries or territories, and the average annual age-standardized death rates decreased within that timeframe in 143 of 195 countries or territories [6]. Thus far, few countries have been able to overcome this challenge. Nevertheless, in the US cancer incidence (for all cancer sites combined) rates have decreased among men and were stable among women. Overall, there continue to be significant declines in cancer death rates among both men and women. With early detection and treatment people survive cancer and are living with several side effects [7].

Heart failure (HF) is a global pandemic affecting about 38 million people and is a growing health problem worldwide [8-10]. Even though the incidence of HF is stable, the prevalence is going to rise because of the ageing population and improvements in treatment $[11,12]$. The HF condition is common in both developing and developed countries; the switch towards a Western lifestyle in developing countries may be contributing to a real HF pandemic. Consequently, HF health expenditures are considerable and will increase dramatically with an ageing population. $\mathrm{HF}$ is one of the most common causes of hospitalization and readmission [13-16]. The prevalence, incidence, mortality and morbidity rates reported show geographic variations, depending on the different aetiologies and clinical characteristics observed among patients with HF. The risk 
factors for $\mathrm{HF}$ are multifactorial and complex, and there is no known prevention other than treatment of the risk factors, such as hypertension, diabetes and obesity; whereas prevention and early treatment strategies (i.e. early revascularization) appear to be effective in reducing the risk and severity of acute myocardial infarction [17].

Moreover, today depression is the most common psychological disorder, affecting about 121 million people in all ages worldwide. WHO states that depression is the leading cause of disability as measured by Years Lived with Disability (YLDs) and the fourth leading contributor to the global burden of disease. By the year 2020, depression is projected to reach the second place in the ranking of Disability Adjusted Life Years (DALY) calculated for all ages.

This demographic development will have consequences both economically, socially, culturally and politically [18]. The health care systems around the globe will face great challenges in the years to come. Health promotive initiatives will become ever more important; not only for people with physical and mental disabilities and older persons living at home or in care facilities, but also among the healthy population in supporting them to stay healthy. Facing these demographic trends, finding new and effective ways to improve people's health globally is imperative. Health promotion should be a vital part of the health care systems.

\subsubsection{The Background of Health Promotion}

WHO has for a long time promoted a common approach to health policy by developing a series of targets for improved health status, i.e. the Health for All Strategy-Targets for Health for All [19]. Several health conferences have been arranged by WHO. Two of the most significant conferences were arranged in Alma Ata in 1978, resulting in the Alma-Ata Declaration, which emerged as a milestone of the twentieth century in the field of public health [20]. The second was arranged in Ottawa, Canada, where 200 del- egates from 38 nations came together and made a commitment to health promotion; based on the Alma-Ata Declaration, the Ottawa Charter for health promotion was born [21]. This charter defined health promotion as 'the process of enabling people to increase control over, and to improve, their health. To reach a state of complete physical mental and social wellbeing, an individual or group must be able to identify and to realize aspirations, to satisfy needs, and to change or cope with the environment' [22]. The Ottawa Charter became a core policy document and a cornerstone in establishing the health promotion field [23].

The Lancet-University of Oslo (UiO) Commission of Global Governance for Health stated that 'health is a precondition, outcome, and indicator of a sustainable society, and should be adopted as a universal value and shared social goal and political objective for all' [24]. According to Samdal and Wold [23], health promotion is a modern ideology and strategy to improve public health. It represents a reorientation of public health from addressing individual risk factors of health or risk behaviours toward targeting determinants of health and empowering individuals and communities to participate in improving the health of their communities $[25,26]$.

'Health promotion is positive and dynamic. It opens up the field of health to become an inclusive social, rather than an exclusive professional activity. It represents a broadening of perspectives in relation to health education and to prevention as a whole' ([27], p. 3). In these words, the former Chair of the Editorial Board of Health Promotion International introduced this new scientific journal in 1986. She was one of the key persons strongly and deeply involved in the discussions of the content of health promotion and how health promotion differs from public health and disease prevention. Some of the key notions of these discussions were summarized in a document by the WHO European Office [28]; Scriven and Orme described this publication as the emergence of health promotion as a major movement [21]. 


\subsubsection{The Core Principles and Strategies of Health Promotion}

Health is seen as a resource of everyday life, not the objective of living. Health is a positive concept emphasizing social and personal resources, as well as physical capacities. The prerequisites for health as the fundamental conditions and resources are peace, shelter, education, food, income, a stable ecosystem, sustainable resources, social justice and equity [22]. Three basic principles for health promotion work from the Ottawa Charter: advocate, enable and mediate.

- Advocate: Political, economic, social, cultural, environmental, behavioural and biological factors can all favour health or be harmful to it. Health promotion action aims at making these conditions favourable through advocacy for health [22].

- Enable: Health promotion focuses on achieving equity in health. Health promotion action aims at reducing differences in current health status and ensuring equal opportunities and resources to enable all people to achieve their fullest health potential. This includes a secure foundation in a supportive environment, access to information, life skills and opportunities for making healthy choices. People cannot achieve their fullest health potential unless they are able to take control of those things which determine their health [22].

- Mediate: The prerequisites and prospects for health cannot be ensured by the health sector alone. Professional and social groups and health personnel have a major responsibility to mediate between differing interests in society for the pursuit of health [22].

The Ottawa Charter clearly stated that a major aim of health promotion is to achieve equity in health by enabling all people to achieve their fullest health potential. To achieve this goal, five core strategies for health promotion action were identified:
1. Build a healthy public policy.

2. Create supportive environments.

3. Strengthen community action.

4. Develop personal skills.

5. Reorient health services.

These principles have stood the test of time, and the first four actions are developing well. However, the principle of 'reorienting health services' has until recently been given less attention. Available evidence guiding the health care services into a more health-promoting direction is still scarce. What does it mean to reorient health services? According to the Ottawa Charter [22], it means that the responsibility for health promotion in health services is shared among individuals, community groups, health professionals, health service institutions and governments. They must work together toward a health care system which contributes to the pursuit of health. Health services need to embrace an expanded mandate which is sensitive to and respects cultural needs. This mandate should support the needs of individuals and communities for a healthier life and open channels between the health sector and broader social, political, economic and physical environmental components. Reorienting health services also requires stronger attention to health research as well as changes in professional education and training. This must lead to a change of attitude and organization of health services, which refocuses on the total needs of the individual as a whole person.

In the special supplement of Health Promotion International entitled 'The Ottawa Charter for Health Promotion 25 years on', a panel of diverse commentators reviewed progress and opportunities. Authors agreed that there had been slow progress in making health promotion a core business for health services, and there was a need to reframe, reposition and renew efforts. One proposal was to focus on reorienting the system itself-not just the delivery of services-by health promotion leaders engaging more actively in system development [29]. In an Editorial in Health Promotion International, John Catford claimed that it is time to reorient health services 
[30]. He expressed that at the time of Ottawa in 1986 the conferees agreed that 'The role of the health sector must move increasingly in a health promotion direction, beyond its responsibility for providing clinical and curative services' ([30], p. 1). What has happened after Ottawa? Twentythree years later 'there still seems to be an urgency towards the empowerment of patients to truly take control over a hospital environment that too often seems counter to their health' ([31], p. 106). This echoed earlier comments that 'across the world there appears to have been stubborn resistance to systematic change in health care services, and only limited examples of effective and sustainable health services reorientation' [32]. Thompson, Watson and Tilford come to the same conclusion after summarizing the efforts done 30 years after the Ottawa ([33], p. 73): 'Although its principles have been widely applauded, opportunities to transfer these principles into the radical changes and practical solutions needed globally to improve health have been missed. Nevertheless, it is argued that the Ottawa Charter retains its relevance to the present day and that all policy makers and professionals working to promote positive health should revisit and take heed of its principles'.

The WHO Regional Office for Europe has further developed basic guiding principles for health promotion work ([34], pp. 4-5) which should be characterized by the following principles:

- Empowering (enabling individuals and communities to assume more power over the personal, socioeconomic, and environmental factors that affect their health).

- Participatory (involving all concerned at all stages of the process).

- Holistic (fostering physical, mental, social and spiritual health).

- Equitable (guiding by a concern for equity and social justice).

- Sustainable (bringing about changes that individuals and communities can maintain once initial funding has ended).

- Multistrategy (using a variety of approaches and methods).
An editorial entitled 'Turn, turn, turn: time to reorient health services' in the Health Promotion International journal ([30], p. 3) emphasized a changed way of working from 'downstream' acute repair - to 'upstream' health improvement and from patient compliance-to consumer control and centredness. This way of working can be visualized by using 'health in the river of life' as a metaphor for health promotion [35].

The river as a metaphor of health development (Fig. 1.1) has often been used. According to Antonovsky, it is not enough to promote health by avoiding stress or by building bridges keeping people from falling into the river. Instead, people have to learn to swim [36]. Lindström and Eriksson (2010) presented Salutogenesis in the context of health promotion research, using a new analogue of a river, 'Health in the River of Life'. The river of life is a simple way to demonstrate the characteristics of medicine (care and treatment) and public health (prevention and promotion) shifting the perspective and the focus from medicine to public health and health promotion toward population health.

The aim of this anthology is to describe and clarify health promotion in the context of health care settings. By doing so, we argue that the most appropriate theoretical foundation for health promotion in health care is the salutogenic theory of health by Antonovsky [36-38]. An integration of salutogenesis in health care could be a way to reorient health services in line with the Ottawa Charter for health promotion [22].

\subsubsection{The Salutogenic Theory as the Foundation of Health Promotion}

In many countries, health promotion has been primarily a field of practice and less a field of research [23]. The Ottawa conference in 1986 established the health promotion field, while the Jakarta conference in 1997 started a discussion of theory-driven approaches and evidence in this field. Throughout the two decades following the Ottawa conference, the health promotion 


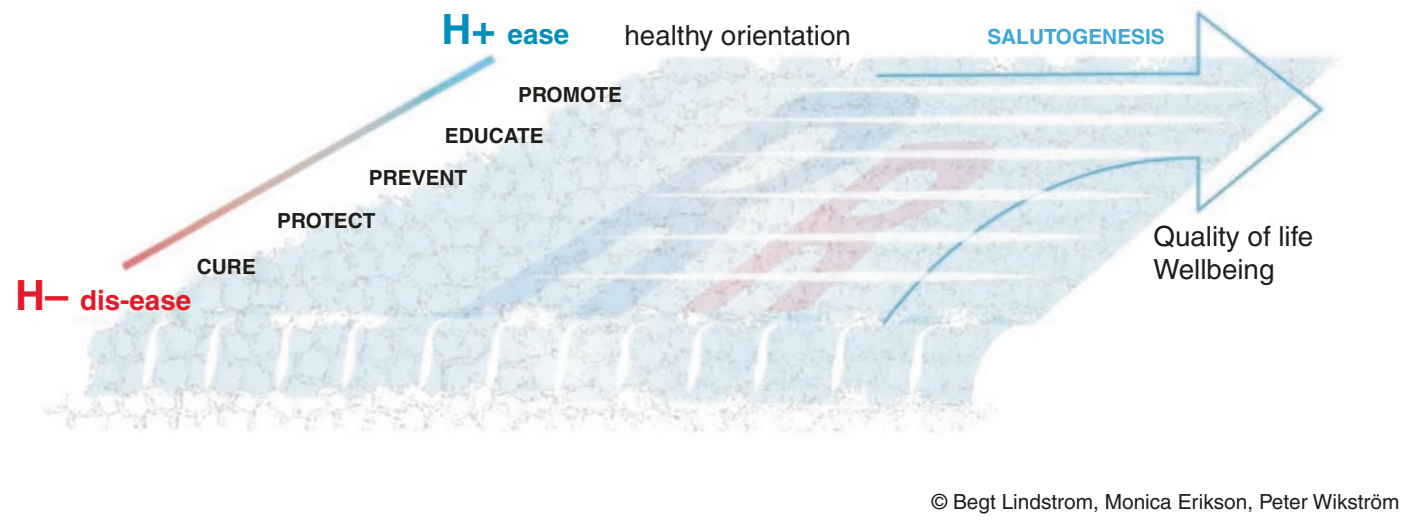

Fig. 1.1 Health in the River of Life. (Published with permission from Folkhälsan Research Center, Helsinki, Lindström \& Eriksson ([35], p. 17))

field has developed from a practice and policy field to also include a stronger theory and research field. There is currently a strong drive toward research-based practice in this field building on numerous evaluations of practices and programmes that have been developed and implemented in the course of these years ([23], p. 7). Samdal and Wold ([23], p. 9) provided an overview of theories relevant to health promotion; at the individual level, numerous concepts and theories in behavioural sciences contribute to the identification of conditions and processes that enable people to develop the personal skills necessary to make healthy choices. Vital psychological phenomena found to influence healthy choices are beliefs, knowledge, selfefficacy, skills, roles, attitudes and values. Important psychosocial concepts include social support, social cohesion, interpersonal stress, significant others and social norms. Social influence processes on health are explained by social psychological theories, such as social learning theory (social cognitive theory), the theory of planned behaviour, the self-determination theory, the social reproduction perspective and various socialization theories (e.g. ecological systems theory). In her lecture, 'The history and the future: towards a new public health' at the conference Next Health in Trondheim, Kickbusch [39] described how people involved in the Ottawa conference were influenced by various theories, both health theories (Antonovsky, Illich, Lalonde) and sociological theories (Giddens, Mead, Foucault). However, the theoretical base for health promotion came in the cloud of more practical health work.

Just before the Ottawa conference in 1986, a special meeting was held in Copenhagen hosted by the WHO Regional Office for Europe. Aaron Antonovsky was invited and participated in the meeting and discussions. Nonetheless, the salutogenic theory did not appear in the formulations of the Ottawa Charter. Tamsma and Costongs ([40], p. 45) from the EuroHealthNet partnership stated that even if much evidence has been generated about the value of health promotion to health systems efficiency, outcomes and sustainability, yet the health (care) sector itself has been unable to adopt a systematic health promotion perspective and integrate it into broader systems and governance. The wide gap between the worlds of promoting health and curing disease remains. The reorientation of health sectors is where least progress from the Ottawa Charter principles can be noted. To conclude, there is still much work to do to implement health promotion into the health care sector in general, and the salutogenic theory and perspective in particular. Therefore, this book provides knowledge on health promotion and the potential role of salutogenesis in order to reorient the health care sector in a health promotion direction. 


\subsubsection{The Ontology of Salutogenesis}

Ontology is the study of reality [41]. What do we know about the ontological background of salutogenesis? In his second book, Unraveling the Mystery of Health [36], Antonovsky described how he perceived the world. Two important things stand: (1) he saw man in interaction with his environment and (2) chaos and change as normal states of life. The former calls for system theory thinking where the focus is on the individual in a context [42, 43]. By the latter, Antonovsky perceived daily life as constantly changing; a heterostatic as opposed to a homeostatic state. For the individual, the challenge is to manage the chaos and find strategies and resources available for coping with the changes in everyday life. As a medical sociologist, he distinctly expressed systems theory thinking, this was a natural way for Antonovsky to perceive the world: seeing humans as part of and in interaction with the environment and context.

\subsubsection{The Epistemology of Salutogenesis}

Epistemology is the study of knowledge [44]. Going back to Antonovsky's writings [36, 37], little insight into his thoughts about knowledge generating and learning is provided. As far as we know, he did not manifest an epistemological basis for salutogenesis, neither describing his view of how knowledge in general arises nor how learning can be meaningful in the salutogenic framework. It appears that he was preoccupied with examining and describing how a strong SOC may have an impact on perceived health. A search in different databases provides little response [43]. Epistemologically, salutogenesis can be conceived as a constant learning process as shown in Fig. 1.2.
Fig. 1.2 Salutogenesis from an epistemological perspective. (With permission from: Eriksson M. The Sense of Coherence in the Salutogenic Model of Health. In: Mittelmark MB, Sagy S, Eriksson M, Bauer G, Pelikan J, Lindström B, et al., editors. The Handbook of Salutogenesis. New York: Springer; 2017. p. 91-6)

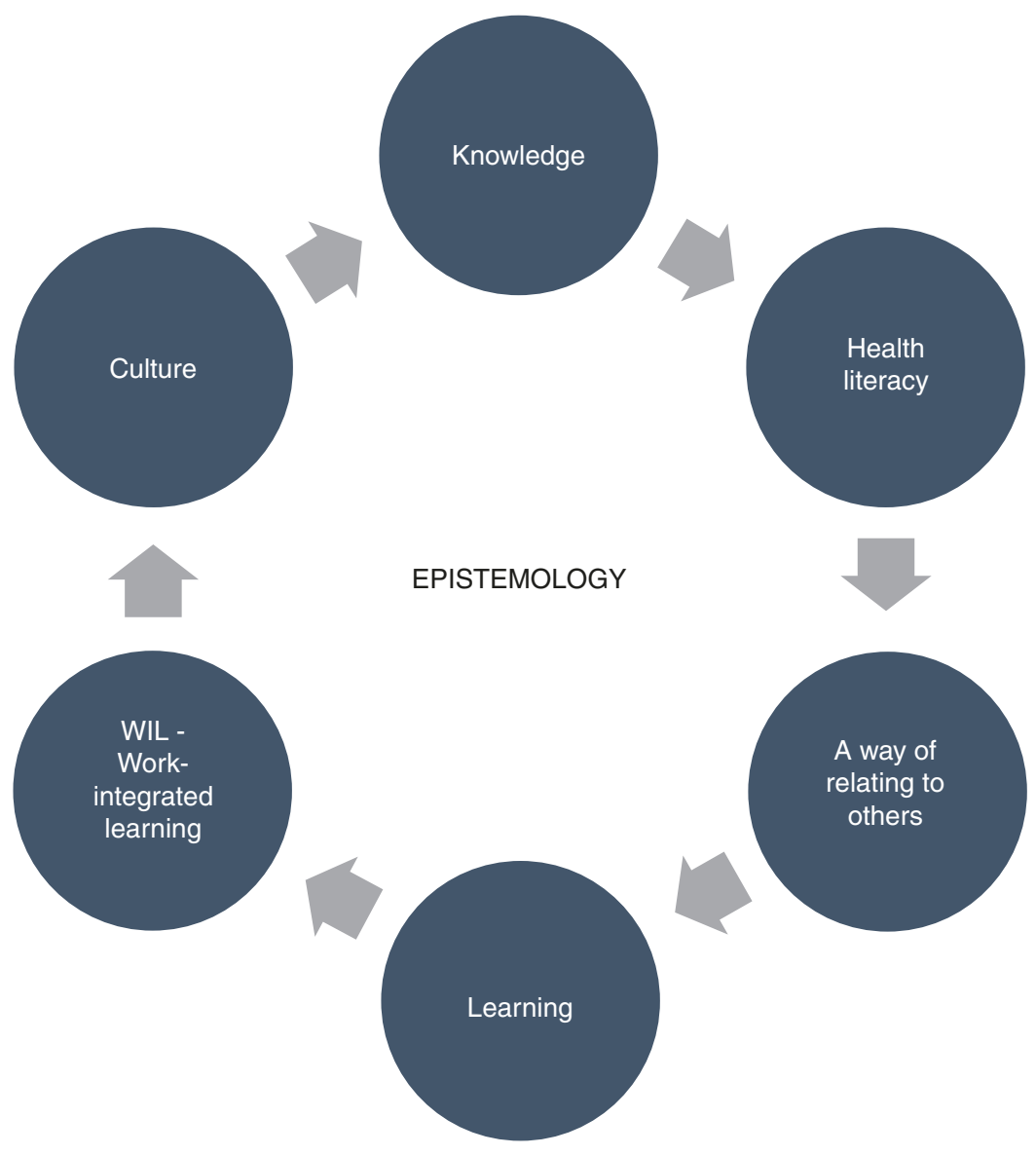


Figure 1.2 portrays that knowledge supports the movement toward the ease pole of the ease/ dis-ease continuum (Fig. 1.3), while knowledge increases health literacy, which facilitates development in the ways one relates to one's world. The process of relating to others produces learning, and the knowledge gained from practice expands one's area of knowledge. In the course of daily life, this integrated learning process is continuous. The concept of work-integrated learning (WIL) is a new concept describing distinctive aspects of pedagogics and learning processes in health care settings [45]. The core of the salutogenic theory is to maintain and even develop health; this happens here and now in the context and culture where people live. To relate to health promotion and the Ottawa Charter for health promotion [22], culture becomes a resource in everyday life.

\subsubsection{Health as a Process in an Ease/ Dis-Ease Continuum}

According to Antonovsky, health is the movement on a continuum between $(\mathrm{H}+$, Fig. 1.3) ease and dis-ease (H-, Fig. 1.3) [46]. He referred to the ability to comprehend the whole situation and the capacity to use the resources available as the sense of coherence (SOC). This capacity was a combination of peoples' ability to assess and understand the situation they were in, to find a meaning to move in a health-promoting direction, also having the capacity to do so-that is, comprehensibility, meaningfulness and the manageability, to use Antonovsky's own terms [43, 47]. In such an approach, no one is categorized as healthy or diseased. Since we are all somewhere between the imaginary poles of total wellness and total illness, the whole population becomes the focus of concern. Even the fully robust, energetic, symptom-free, richly functioning individual has the mark of mortality: he or she wears glasses, has moments of depression, comes down with flu and may also have yet non-detectable malignant cells. Even the terminal patient's brain and emotions may be fully functional. The great majority of us are somewhere between the two poles. The idea of movement along an ease/disease continuum is illustrated in Fig. 1.3.

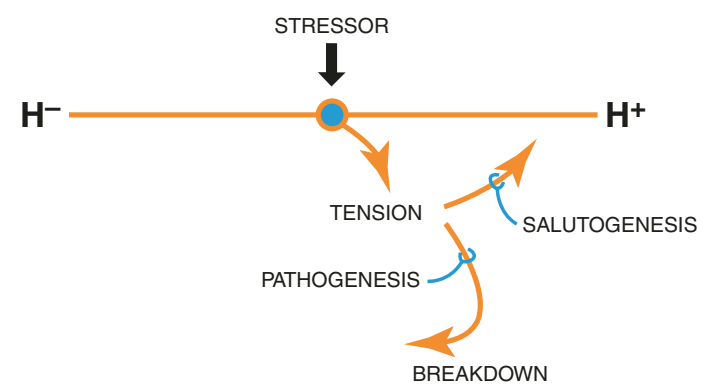

Fig. 1.3 The ease/dis-ease continuum [36, 37]. (Published with permission from Folkhälsan Research Center, Helsinki, Bengt Lindström, Monica Eriksson, Peter Wikström [35])

Antonovsky assumed that we constantly are exposed to changes and events that may be considered as stressors. This may involve major life events such as when someone in the family falls ill, changes in the family (e.g. a divorce) or changes in the workplace (organizational changes or unemployment). Theories on stress and coping are mainly focused on the concept of control. However, the concept of control is not central in the salutogenic theory. According to Antonovsky, who can control life? To use Antonovsky's own words, the salutogenic view of stress and coping includes the following:

... life is inherently full of stressors, with lifesituation stressor complexes by far deserving most of our attention if we wish to understand either health or disease. Focusing on health, I expressly rejected the implicit assumption that stressors are inherently pathogenic. Their health consequences can only be understood if we understand the coping process ([48], p. 48)

\subsubsection{The Key Concepts of the Salutogenic Theory}

Three key concepts form the salutogenic theory: (1) sense of coherence and (2) generalized and (3) specific resistance resources (described more in detail in Part I, Chap. 2 and Part II, Chap. 4).

Sense of coherence (SOC): Based on the interviews with Israeli women about health and how they were able to adapt to life events they went through, an important factor emerged: the sense of coherence. It reflects a person's view of life 
and capacity to respond to stressful situations. The original definition by Antonovsky [36] is as follows:

\begin{abstract}
SOC is a global orientation that expresses the extent to which one has a pervasive, enduring though dynamic feeling of confidence that (1) the stimuli from one's internal and external environments in the course of living are structured, predictable, and explicable; (2) the resources are available to one to meet the demands posed by these stimuli; and (3) these demands are challenges, worthy of investment and engagement. (p. 19)
\end{abstract}

Behind a global orientation, SOC is a way of viewing life as structured, manageable, and meaningful. At least three dimensions form the SOC: comprehensibility, manageability and meaningfulness. It is a personal way of thinking, being and acting, with an inner trust, which leads people to identify, benefit, use, and re-use the resources at their disposal [49].

Generalized and Specific Resistance Resources (GRR and SRR): Along with the SOC, the other key concepts in the salutogenic theory are the resistance resources [36, 37], including generalized resources (potentially available for engagement in a wide range of circumstances) and specific resources (particular resources relevant to particular circumstances). The resistance resources are of a different nature: among others genetic and constitutional, psychosocial, cultural and spiritual, material and a preventive health orientation [47]. Resistance resources exist at the individual, the group (family), the subculture and the whole society levels ([37], p. 103) and represent the prerequisites for developing a strong SOC.

\subsubsection{Salutogenesis Is More Than the Measurement of the SOC}

Salutogenesis is an area of knowledge and learning, a way of relating to others and a way of working in a health-promoting manner [43]. First and foremost, salutogenesis is a resource-oriented approach focusing on health and on people's abilities and capacities. Currently, there is extensive research that focuses on the resources of individuals, groups, and communities; this includes much more than the measurement of the SOC. Today, we talk about salutogenesis as a model of health and a life orientation (the SOC) [50], as well as the salutogenic conceptual framework. Salutogenesis now represents an umbrella concept with many different theories and concepts with salutogenic elements and dimensions [35]. Several of these concepts are highlighted in this anthology in Chaps. 4-18 and shown in bold fonts in Fig. 1.4.

Certain trends in the salutogenic research can be identified. These are (1) the translation and validation of the original SOC questionnaires (29 and 13 items), to other languages than English, (2) the use of the SOC questionnaires in different areas of research, (3) the term theory is more frequently used instead of idea of health and health model. What is a theory? The development of a theory begins with an idea, continues via various models, development of questionnaires, testing in empirical practice, systematically synthesize research, new instruments and insights. When all these steps take place in a systematic order, a theory arises. Such a development can be seen according to the salutogenic theory. Further, (4) development of programmes and interventions aiming at strengthening the SOC among patients and professionals and (5) the use of the SOC questionnaire for the evaluation of the effectiveness of interventions. The SOC questionnaire has been used in different areas compared to when the research began. Examples of new areas are oral health, health behaviour and work-life research. Currently, a tendency to move from only measuring SOC to applying salutogenic principles into practice when programmes and interventions are planned in various settings can be seen; such promising approaches among different populations in the health care are presented in Part III of this book; examples are the SHAPE intervention among older community-dwelling people (Chap. 23), the inter-generational platform intervention study in Singapore (Chap. 24), nurse-patient interaction as a health promotion approach in nursing homes (Chap. 10) and the 


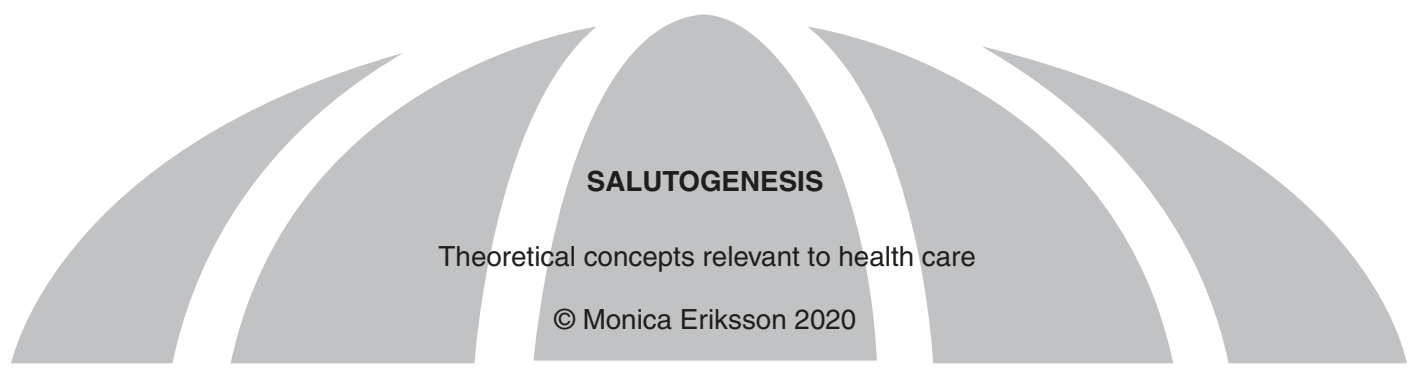

\title{
Social support | Empowerment | Flourishing | Sense of Coherence | Dignity | Belonging Self-efficacy | Self-transcendence | Hope | Will to meaning | Willpower | Connectedness Salutogenic nursing | Nurse-patient interaction | Person-centered care | Inner strength Bodyknowledging | Coping
}

\author{
Reasonableness | Resilience | Learned resourcefulness | Attachment | Empathy | Wellbeing \\ | Learned hopefulness | Humour | Gratitude | Quality of Life | Flow | Hardiness | Social capital \\ Locus of Control | Ecological system theory | Interdisciplinarity | Cultural capital | Thriving \\ Posttraumatic Personal Growth | Learned optimism | Slow nursing
}

Fig. 1.4 Salutogenesis. Theoretical concepts relevant to health care

bodyknowledging among chronical ill (Chap. 16). This implies that along the original SOC questionnaires, a range of different questionnaires have been developed and validated for use in the field of health promotion research. This is promising. As presented earlier in this chapter, due to the demographic development worldwide, the health care systems in all countries will face great challenges in the years to come. Facing the demographic trends, finding new and effective ways to improve people's health globally is imperative. Hence, health promotive initiatives will become ever more important worldwide.

\section{References}

1. Kinsella K, He W. An Aging World: 2008. Washington, DC: U.S. Department of Health and Human Services National Institutes of Health National Institute on Aging, U.S. Department of Commerce Economics and Statistics; 2009. Contract No.: Report No.: P95/09-1.

2. WHO. World report on ageing and health. Geneva: WHO; 2018. https://www.who.int/news-room/factsheets/detail/ageing-and-health. Accessed 5 Feb 2018.
3. WHO. Global status report on non-communicable diseases. 2010. http://www.who.int/chp/ncd_global_ status_report/en/index.html. Accessed 23 Aug 2012.

4. WHO. Global strategy and action plan on ageing and health. IGO LCB-N-S, editor. Geneva: World Health Organization; 2017.

5. Prince M, Wimo A, Guerchet M, Ali G-C, Wu Y-T, Prina M. World Alzheimer Report 2015: The Global Impact of Dementia. An analysis of prevalence, incidence, cost and trends. London: Alzheimer's Disease International; 2015.

6. Global Burden of Disease Cancer Collaboration, Fitzmaurice C, Akinyemiju TF, et al. Global, regional, and national cancer incidence, mortality, years of life lost, years lived with disability, and disabilityadjusted life-years for 29 Cancer Groups, 1990 to 2016: a systematic analysis for the Global Burden of Disease Study. JAMA Oncol. 2018;4(11):1553-68.

7. Cronin KA, Lake AJ, Scott S, Sherman RL, Noone AM, Howlader N, et al. Annual report to the nation on the status of Cancer, part I: National Cancer Statistics. Cancer. 2018;124(13):2785-800.

8. Ponikowski P, Anker S, AlHabib K, Cowie M, Force $\mathrm{T}, \mathrm{Hu} \mathrm{S}$, et al. Heart failure: preventing disease and death worldwide. ESC Heart Fail. 2014;1(1):4-25.

9. Heidenreich P, Trogdon J, Khavjou O, Butler J, Dracup K, Ezekowitz M, et al. Forecasting the future of cardiovascular disease in the United States: a policy statement from the American Heart Association. Circulation. 2011;123(8):933-44.

10. Reyes E, Ha J, Firdaus I, Ghazi A, Phrommintikul A, Sim D, et al. Heart failure across Asia: same health- 
care burden but differences in organization of care. Int J Cardiol. 2016;2016(223):163-7.

11. Rajadurai J, Tse H, Wang C, Yang N, Zhou J, Sim D. Understanding the epidemiology of heart failure to improve management practices: an Asia-Pacific perspective. J Card Fail. 2017;23(4):327-39.

12. Richards A, Lam C, Wong R, Ping C. Heart failure: a problem of our age. Ann Acad Med Singapore. 2011;40(9):392-3.

13. Bundkirchen A, Schwinger R. Epidemiology and economic burden of chronic heart failure. Eur Heart J Suppl. 2004;6:D57-60.

14. Kannel W. Incidence and epidemiology of heart failure. Heart Fail Rev. 2000;5(2):173-7.

15. Ng T, Niti M. Trends and ethnic differences in hospital admissions and mortality for congestive heart failure in the elderly in Singapore, 1991 to 1998 . Heart. 2003;89(8):865-70.

16. Santhanakrishnan R, Ng T, Cameron V, Gamble G, Ling L, Sim D, et al. The Singapore heart failure outcomes and phenotypes (SHOP) study and prospective evaluation of outcome in patients with heart failure with preserved left ventricular ejection fraction (PEOPLE) study: rationale and design. J Card Fail. 2013;19(3):156-62.

17. Savarese G, Lund LH. Global public health burden of heart failure. Card Fail Rev. 2017;3(1):7-11.

18. United Nations. World Population Ageing: 19502050. New York: United Nations, Department of Economic and Social Affairs; 2002. www.un.org/esa/ population/publications/worldageing 19502050.

19. WHO. Targets for health for all 2000. Copenhagen: WHO Regional Office for Europe; 1986b.

20. WHO. Primary health care: report of the international conference on primary health care Alma-Ata, USSR. Geneva: WHO; 1978.

21. Scriven A, Orme J, editors. Health promotion-professional perspectives. New York: Palgrave/The Open University; 2001.

22. WHO. The Ottawa charter for health promotion: an international conference on health promotion. The Move towards a New Public Health. Copenhagen: WHO; 1986c.

23. Samdal O, Wold B. Introduction to health promotion. In: Wold B, Samdal O, editors. An ecological perspective on health promotion systems, settings and social processes. Sharjah: Bentham Science; 2012. p. 3-10.

24. The Lancet-University of Oslo Commission on Global Governance for Health. The political origins of health inequity: prospects for change. Lancet. 2014;383:630-67.

25. Kickbusch I. The contribution of the World Health Organization to a new public health and health promotion. Am J Public Health. 2003;93(3):383-8.

26. Mittelmark MB, Kickbush I, Rootman I, Scriver A, Tones K. Health promotion. In: Heggenhougen K, Quah S, editors. International encyclopedia of public health. San Diego, SD: Academic Press; 2008. p. 225-39.
27. Kickbusch I. Introduction to the journal. Health Promot Int. 1986;1(1):3-4.

28. WHO. Health promotion. A discussion document on the concept and principles. Copenhagen: WHO Regional Office for Europe; 1986a.

29. Ziglio E, Simpson S, Tsouros A. Health promotion and health systems: some unfinished business. Health Promot Int. 2011;26:ii216.

30. Catford J. Turn, turn, turn: time to reorient health services. Health Promot Int. 2014;29(1):1-4.

31. De Leeuw E. Have the health services reoriented at all? Health Promot Int. 2009;24(2):105-7.

32. Wise M, Nutbeam D. Enabling health systems transformation: what progress has been made in re-orienting health services? Promot Educ. 2007;2:23-7.

33. Thompson S, Watson M, Tilford S. The Ottawa charter 30 years on: still an important standard for health promotion. Int $\mathrm{J}$ Health Promot Educ. 2018;56(2):73-84.

34. Rootman I, Goodstadt M, Hyndman B, McQueen D, Potvin L, Springett J, et al., editors. Evaluation in health promotion principles and perspectives. Copenhagen: World Health Organization; 2001.

35. Lindström B, Eriksson M. The Hitchhiker's guide to Salutogenesis. Salutogenic pathways to health promotion. Folkhälsan Research Center: Helsinki; 2010.

36. Antonovsky A. Unraveling the mystery of health. How people manage stress and stay well. San Fransisco: Jossey-Bass; 1987.

37. Antonovsky A. Health, stress, and coping: new perspectives on mental health and physical wellbeing. San Francisco, CA: Jossey-Bass; 1979.

38. Mittelmark MB, Sagy S, Eriksson M, Bauer GF, Pelikan JM, Lindström B, et al., editors. The handbook of Salutogenesis. New York: Springer; 2017.

39. Kickbusch I. The history and the future: towards a new public health. Trondheim: Next Health; 2014.

40. Tamsma N, Costongs C. Promoting health and Wellbeing in the context of the United Nations sustainable development agenda, on behalf of the EuroHealthNet partnership, EuroHealthNet, Brussels. Belg Scand J Publ Health. 2018;46:44-8.

41. Heil J. From an ontological point of view. Gloucestershire: Clarendon; 2005.

42. Antonovsky A. The life cycle, mental health and the sense of coherence. Isr J Psychiatry Relat Sci. 1985;22(4):273-80.

43. Eriksson M. The sense of coherence in the Salutogenic model of health. In: Mittelmark MB, Sagy S, Eriksson M, Bauer G, Pelikan J, Lindström B, et al., editors. The handbook of Salutogenesis. New York: Springer; 2017. p. 91-6.

44. Epistemology AR. A contemporary introduction to the theory of knowledge. New York: Routledge; 2011.

45. Pennbrant S, Svensson L. Nursing and learning-healthcare pedagogics and work-integrated learning. Higher Educ Skills Work Based Learn. 2018;8(2):179-94. 
46. Antonovsky A. The structure and properties of the sense of coherence scale. Soc Sci Med. 1993;36:969-81.

47. Lindström B, Eriksson M. Salutogenesis. J Epidemiol Community Health. 2005;59(6):440-2.

48. Antonovsky A. Can attitudes contribute to health? Advances. J Mind Body Health. 1992;8(4):33-49.

49. Eriksson M, Lindström B. Antonovsky's sense of coherence scale and the relation with health: a sys- tematic review. J Epidemiol Community Health. 2006;60(5):376-81.

50. Mittelmark MB, Bauer G. The meanings of Salutogenesis. In: Mittelmark MB, Sagy S, Eriksson M, Bauer G, Pelikan J, Lindström B, et al., editors. The handbook of Salutogenesis. New York: Springer; 2017. p. 7-13.

Open Access This chapter is licensed under the terms of the Creative Commons Attribution 4.0 International License (http://creativecommons.org/licenses/by/4.0/), which permits use, sharing, adaptation, distribution and reproduction in any medium or format, as long as you give appropriate credit to the original author(s) and the source, provide a link to the Creative Commons license and indicate if changes were made.

The images or other third party material in this chapter are included in the chapter's Creative Commons license, unless indicated otherwise in a credit line to the material. If material is not included in the chapter's Creative Commons license and your intended use is not permitted by statutory regulation or exceeds the permitted use, you will need to obtain permission directly from the copyright holder. 